\title{
Evaluation of earthquake parameters used in the Indonesian Tsunami Early Warning System
}

\author{
Madlazim • Tjipto Prastowo
}

Received: 8 October 2015/Accepted: 8 January 2016/Published online: 18 February 2016

(C) The Author(s) 2016. This article is published with open access at Springerlink.com

\begin{abstract}
Twenty-two of a total of 30 earthquake events reported by the Indonesian Agency for Geophysics, Climatology and Meteorology during the time period 2007-2010 were falsely issued as tsunamigenic by the Indonesian Tsunami Early Warning System (Ina-TEWS). These 30 earthquakes were of different magnitudes and occurred in different locations. This study aimed to evaluate the performance of the Ina-TEWS using common earthquake parameters, including the earthquake magnitude, origin time, depth, and epicenter. In total, 298 datasets assessed by the Ina-TEWS and the global centroid moment tensor (CMT) method were assessed. The global CMT method is considered by almost all seismologists to be a reference for the determination of these parameters as they have been proved to be accurate. It was found that the earthquake magnitude, origin time, and depth provided by the Ina-TEWS were significantly different from those given in the global CMT catalog, whereas the latitude and longitude positions of the events provided by both tsunami assessment systems were coincident. The performance of the Ina-TEWS, particularly in terms of accuracy, remains questionable and needs to be improved.
\end{abstract}

Madlazim · T. Prastowo

Department of Physics, Faculty of Mathematics and Natural Sciences, Universitas Negeri Surabaya, Surabaya 60231, Indonesia

\section{Madlazim $(\bowtie) \cdot T$. Prastowo}

Research Center for Earth Science Studies, Faculty of

Mathematics and Natural Sciences, Universitas Negeri Surabaya,

Surabaya 60231, Indonesia

e-mail: madlazim@unesa.ac.id
Keywords Ina-TEWS - GLOBAL centroid moment tensor catalog · Performance · Accuracy · Earthquake parameters

\section{Introduction}

Indonesia has an Indonesian Tsunami Early Warning System (Ina-TEWS) since 2008. The Ina-TEWS has used automatic processing on hypocenter, $M_{\mathrm{Wp}}$, and local magnitude $\left(M_{\mathrm{L}}\right)$. If earthquake occurred in the ocean, depth $<70 \mathrm{~km}$ and magnitude $>7$, then Ina-TEWS announces early warning that the earthquake can generate tsunami. The Ina-TEWS has been set up to produce tsunami warning in 5 min after the earthquake. This scenario is based on the experience of local tsunami, where the first tsunami attacks the coast within 20-40 min after the earthquake. To reach the goal, it requires 160 broadband seismic stations, 500 accelerograph stations, 60 tide gauges, 20 DART buoys, and several continuous GPS stations for monitoring purposes. The whole Ina-TEWS system consists of four subsystems, namely 1 . monitoring, 2 . processing, 3 . dissemination, and 4. preparedness. The monitoring system has three types of network: 1. earthquake monitoring, 2. sea monitoring, and 3. Earth deformation (Harjadi and Fauzi 2012).

The Ina-TEWS has been directly operated and managed by the Indonesian Agency for Geophysics, Climatology and Meteorology (BMKG). This system automatically processes the magnitude, origin time, depth, and epicenter of an earthquake event as it occurs with the aim of predicting the hazards of a tsunami. The Ina-TEWS uses the Richter scale value, frequently referred to as the $M_{\mathrm{L}}$, to rapidly determine the magnitude of a particular tsunamigenic earthquake, and uses other important parameters, 
such as the origin time, depth, and epicenter, to assess the earthquake. Based on these parameters, the BMKG issued tsunami warnings for 22 events out of a total of 30 earthquakes occurred between 2007 and 2010 (Fig. 1); however, these were all false warnings as a result of inaccuracies in the assessment. In this context, false warnings could be issued for tsunamis that did not occur after sufficiently large earthquakes with magnitudes $>6.5$. Equally, earthquake events with relatively small magnitudes could generate tsunamis, despite a warming not being issued. The assessment of the hazards of a tsunami based on this local magnitude method differs significantly from the moment magnitude method $\left(M_{\mathrm{W}}\right)$, particularly when it is used to analyze events of magnitudes $\geq 6$ (Boore et al. 1997; McCalpin 2010, Appendix 1). The moment magnitude is considered to be a rigorous, accurate measurement of magnitude for large earthquakes with a strength $\geq 6.5$, but takes at least $2 \mathrm{~h}$ to determine the magnitude of such earthquakes (Delouis et al. 2009; Lomax and Michelini 2009), which is a relatively long time for application in a tsunami early warning system. Ulutas et al. (2012) and Ulutas (2013) found that the average slip parameter was calculated to be $4.76 \mathrm{~m}$ according to the seismic moment of the earthquake.

The most accurate method of determining the magnitude of major earthquakes is by using the moment tensor. This includes the GLOBAL centroid moment tensor (CMT) method, commonly known as $M_{\mathrm{W}}$, which also provides the origin time, epicenter, and depth of the earthquake event. The global CMT is currently the most powerful, accurate method of determining earthquake magnitude (Dziewonski et al. 1981; Ekström 1994). The procedures for running the method are based on the measurements of the long period body seismic waves and the recorded surface waves (Kawakatsu 1995). This research aims to determine the differences between the Ina-TEWS and the global CMT methods in determining the parameters: magnitude, origin time, epicenter, and depth.

\section{Methods}

The datasets used in this study were all earthquake events that occurred in Indonesia between 2012 and 2015. These datasets are available at https://inatews.bmkg.go.id/ and were used in this study with permission of the Puslitbang BMKG authority. Seismic station used in this study is BMKG-net, as shown in Fig. 2.

Using these data, we linearly fitted relationship between local magnitude $M_{\mathrm{L}}$ issued by BMKG and moment magnitude issued by Global CMT and found relation between $M_{\mathrm{L}}$ and $M_{\mathrm{W}}$ as $M_{\mathrm{W}}=0.91 M_{\mathrm{L}}+0.36$ with a standard deviation of 0.2 . This $M_{\mathrm{W}}$ is the predicted value. The relation between $M$ and $M_{\mathrm{W}}$ is shown in Fig. 3 .

Then, we compared the $M_{\mathrm{W}}$ predicted and original $M_{\mathrm{W}}$ data. We analyzed and compared the magnitudes, origin times, and depths of all the events using the Data Tool program, an open source physics (OSP) tool, freely available at http://www.opensourcephysics.org/webdocs/Tools. $\mathrm{cfm} ? \mathrm{t}=$ Datatool. This program is a data analysis tool that is
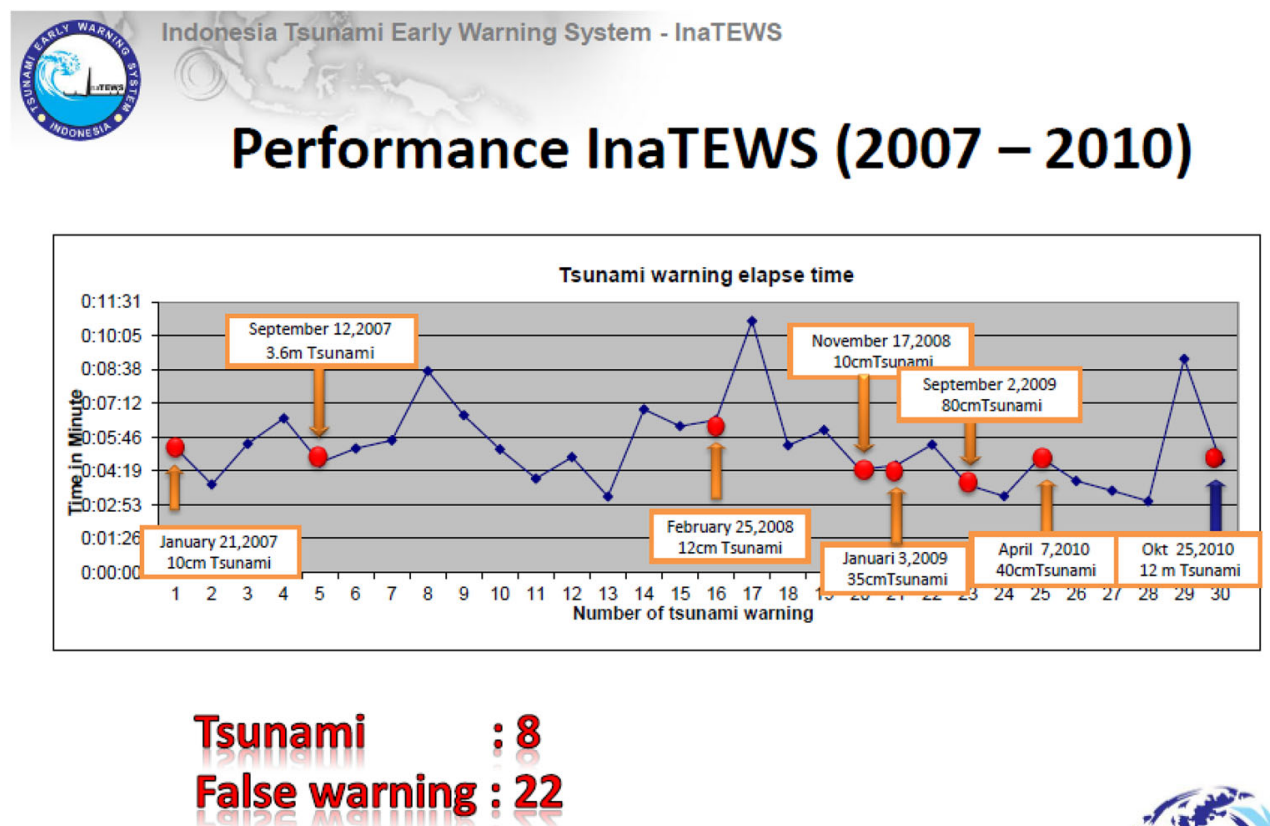

Fig. 1 Ina-TEWS performance during 2007-2010 (Source http://jexp.main.jp/h24soukai/Indonesia.pdf) 


\section{PETA JARINGAN STASIUN SEISMIK YANG DIGUNAKAN OLEH BMKG}

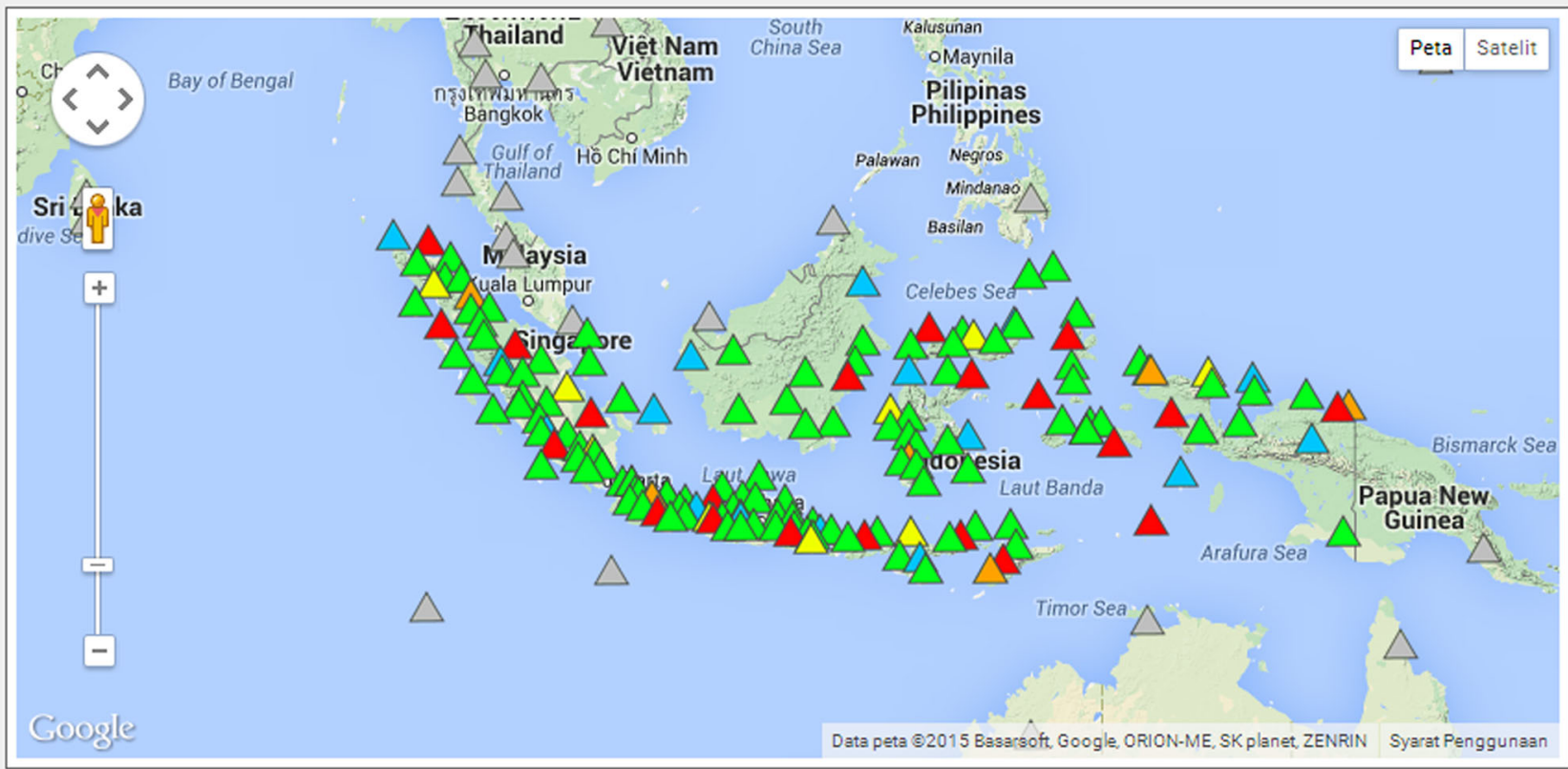

\begin{tabular}{|c|c|c|c|}
\hline & LEGENDA SIMBOL & $\mathbf{U}$ & \\
\hline$\triangle$ & Station Group Libra (Indonesia) & & \\
\hline$\triangle$ & Station Group Jisnet (Jepang) & & \\
\hline$\Delta$ & Station Group GFZ (Jerman) & & $\overline{\bar{\nu}}$ \\
\hline$\triangle$ & Station Group CTBTO (INA) & & 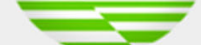 \\
\hline$\triangle$ & Station Group CEA (China) & & $\mathbf{R M K G}$ \\
\hline$\triangle$ & Station Group Luar Negeri & & \\
\hline
\end{tabular}

Fig. 2 Seismic station used in this study (BMKG-net)

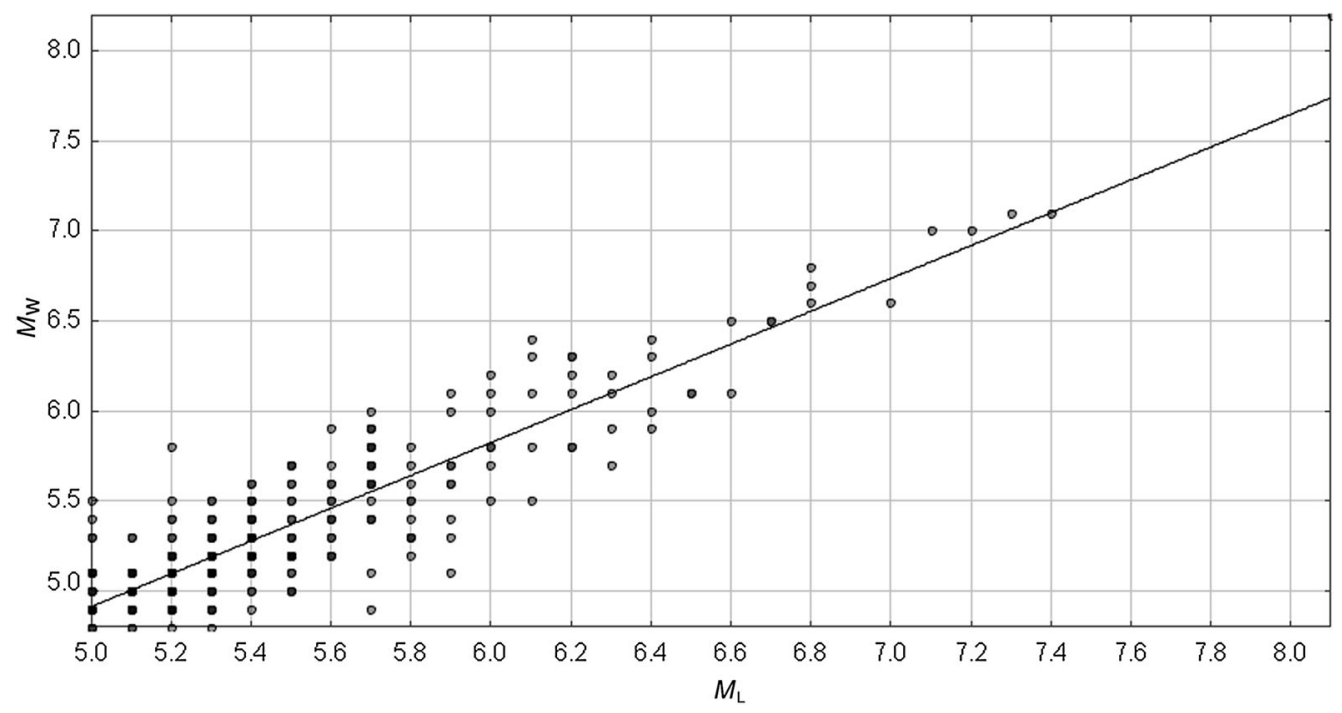

Fig. 3 Relation between $M_{\mathrm{L}}$ and $M_{\mathrm{W}}$ with a standard deviation of 0.2 


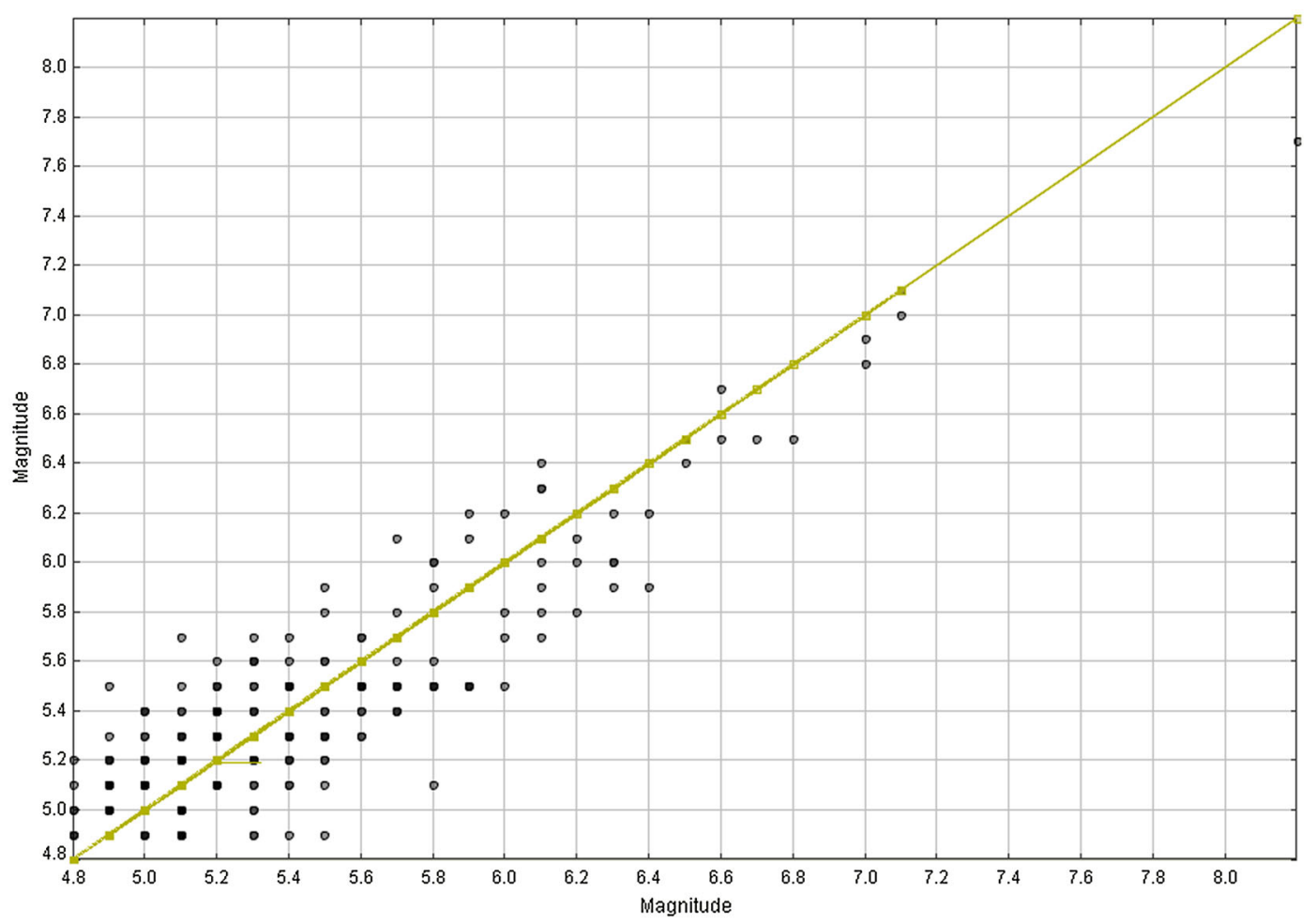

Fig. 4 Comparison of earthquake magnitudes measured by the BMKG (black circles) and with the reference straight line provided by the Global CMT catalog. Earthquake events for which the same magnitude was measured by both institutions are marked on the line as yellow. Both data have standard deviation of 0.2 . For making the line reference with gradient $=1, x$ and $y$ axes must be made same magnitude data, Global CMT data

used to plot and fit data from datasets organized into columns to give a visually simple graphic display. We also used the generic mapping tools freely available at http:// gmt.soest.hawaii.edu/ to manipulate the geographical and cartesian datasets when plotting a map of the earthquake epicenters.

\section{Results and discussion}

We compared the common earthquake parameters (magnitudes, origin times, depths, and epicenters) used in the BMKG and the GLOBAL CMT methods for all earthquakes occurred in Indonesia between 2012 and 2015. Figure 4 shows a comparison between $M_{\mathrm{W}}$ predicted from $M_{\mathrm{L}}$ and $M_{\mathrm{W}}$ original data. Distributions of earthquake magnitudes for all events issued by the BMKG are represented as closed red circles. Figure 4 also shows a yellow straight line representing the magnitude measurements given in the Global CMT catalog $\left(M_{\mathrm{W}}\right.$ original data). The black circles are those events recorded by the BMKG that converted to $M_{\mathrm{W}}$ predicted. As the majority of earthquakes of magnitude 4.8-7.1 plot away this reference line, we concluded that the magnitudes measured by these two authorities did not agree well one to another.

Figure 5 shows the origin time data estimated by the BMKG as red histograms. The blue histograms represent the data provided by the Global CMT catalog. As with the magnitude measurements, a large number of the red histograms plot away from the blue histograms, and thus the origin time measurements given by the two institutions are clearly different from the standard deviation for the both data being $6.5 \mathrm{~min}$. The estimates of the origin times need to be as accurate as possible for a tsunami early warning to minimize risks to the population. With respect to this, the data for the origin time provided by the BMKG during the four years from 2012 to 2015 are not reliable.

Figure 6 demonstrates another significant difference in depth measurements between the BMKG results and the Global CMT catalog. A large deviation was observed between the measured depths issued by the BMKG and the reference depths given by the Global CMT catalog, particularly for depths $<100 \mathrm{~km}$. This is of particular concern because the Ina-TEWS releases a warning for events occurring at depths $<100 \mathrm{~km}$. Thus, the depth estimates provided by the Ina-TEWS are also questionable. 


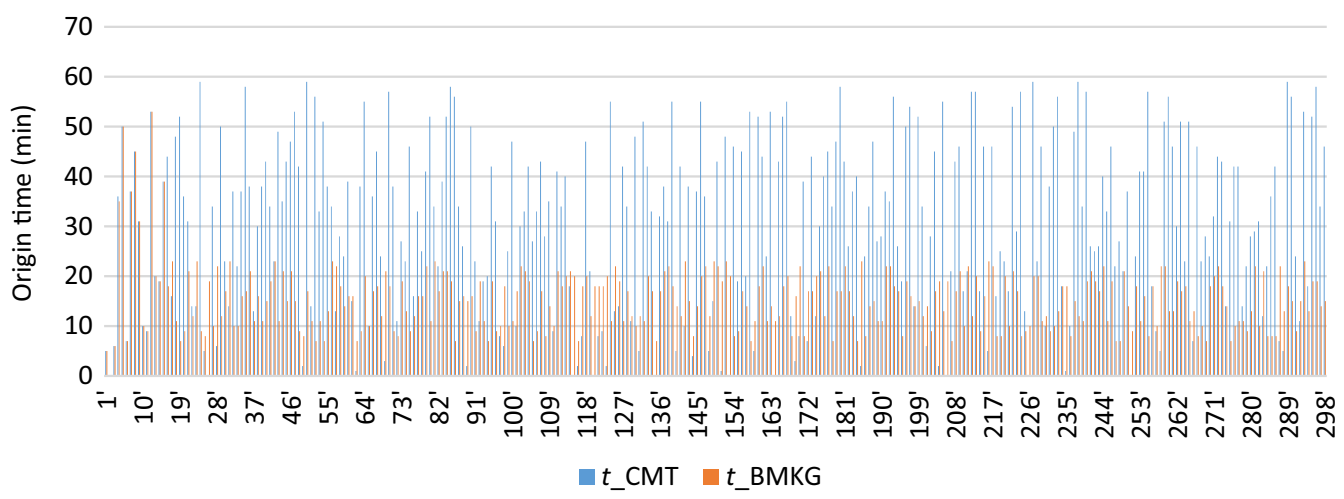

Fig. 5 Comparison of 298 data events for origin times (in minutes) issued by the BMKG (red histograms) and the data series provided by the Global CMT catalog (blue histograms). Standard deviation for the both data is $6.5 \mathrm{~min}$

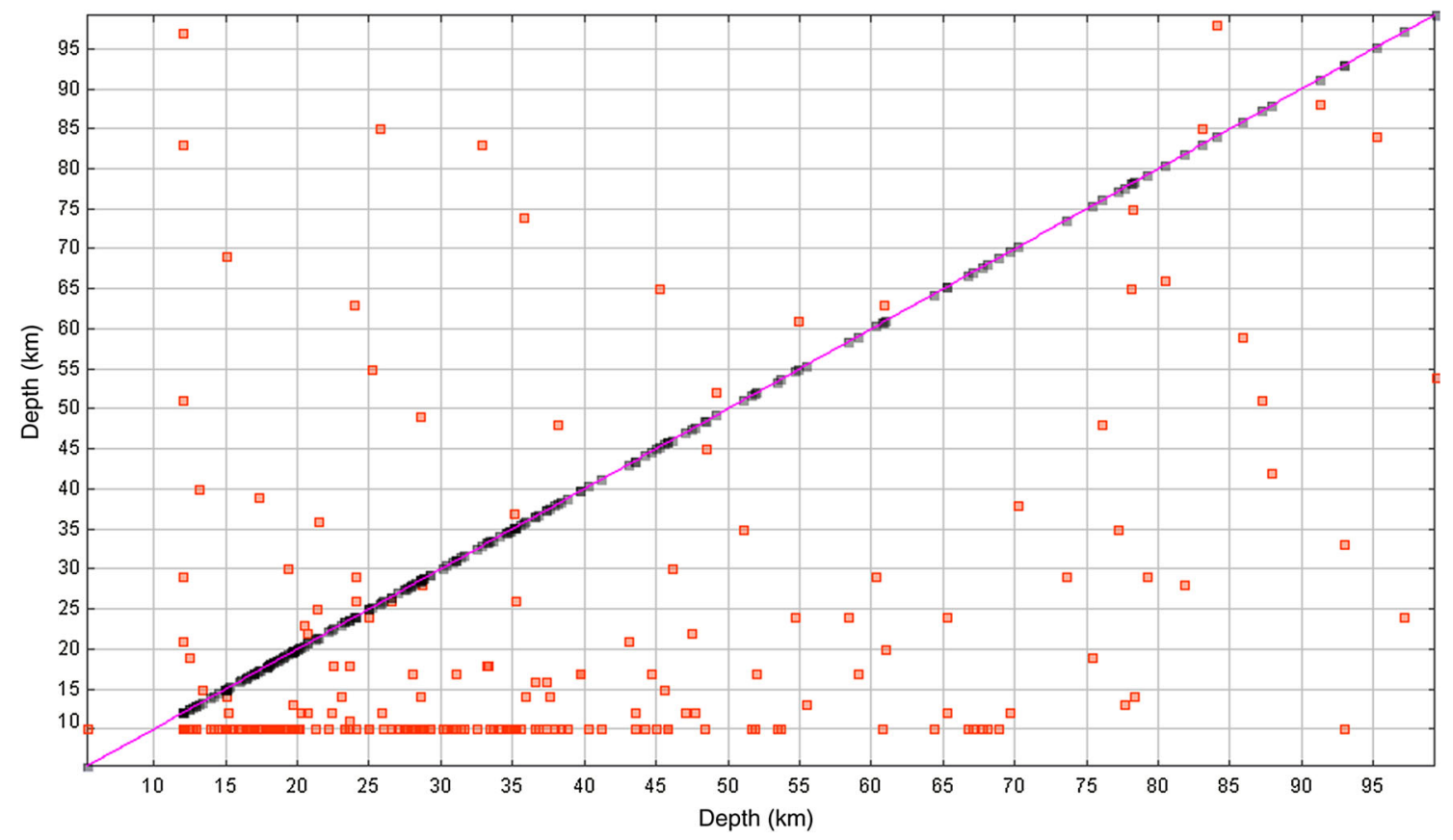

Fig. 6 Comparison of data of depth measurements recorded by the BMKG (red squares) and the reference black line provided by the Global CMT catalog. Earthquake events for which the same depth was measured by both institutions are almost zero. For making the line reference with gradient $=1, x$ and $y$ axes must be made same depth data, Global CMT data

In contrast, the data given by the BMKG for the epicenters of all events from 2012 to 2015 were consistent with those provided by the Global CMT catalog. This is clearly shown in Fig. 7. This figure shows the distribution of earthquake epicenters from the west in northern Sumatra (including Aceh and the west coast of Sumatra) to the east, (including the northern parts of Sulawesi, Maluku, and Papua). Each location given by the BMKG is marked as a red star, and the pattern is very similar to that given by the data from the Global CMT catalog, marked as blue stars.
One plausible reason for the coincidence of these data from the two institutions is that the earthquake epicenters were determined by either seismic stations or satellites using measurements at the Earth's surface. These data had much lower disturbance from noise than the measurements of the other parameters, such as magnitude, origin time, and depth.

As only one of the parameters measured by the BMKG agrees well with the data from the Global CMT catalog, we cannot rely on the earthquake analyses obtained from the 


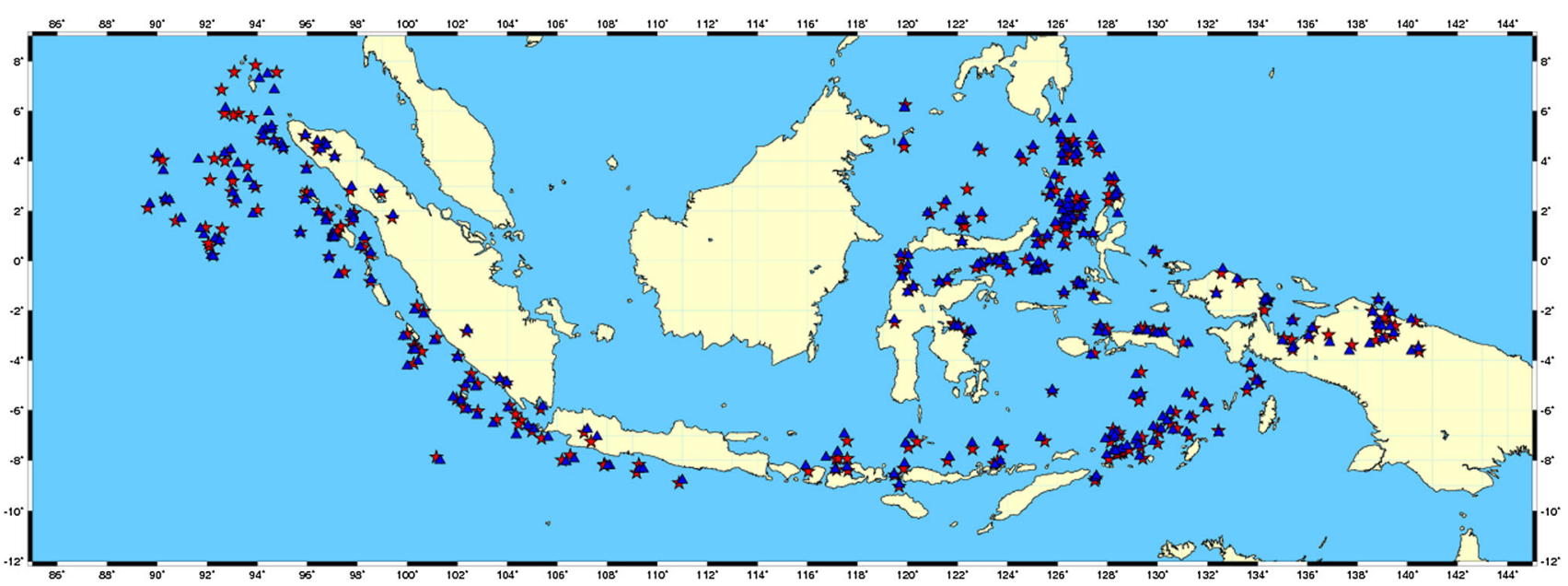

Fig. 7 Map showing the distribution of earthquake epicenters predicted by BMKG using Ina-TEWS for automatic processing when an event occurs (red stars) and distribution of epicenters from all cases provided by the Global CMT catalog (blue stars)

data provided by the BMKG. To give a better prediction of potentially tsunamigenic events at various depths and magnitudes as well as better estimates of origin times and epicenters, we need to propose some new parameters. Madlazim (2011, 2013) and Madlazim et al. (2015) emphasized that the rapid acquisition of high-accuracy information is essential in the assessment of the hazards of a tsunami to minimize false warnings that may lead to poor decision-making in hazard mitigation.

The two main factors required for a tsunami alert triggered by a major earthquake below sea level are accuracy and the rapid delivery of information. The shortcomings of the BMKG method must be overcome before the magnitude of a destructive tsunamigenic earthquake can be assessed accurately and quickly, the key attributes required in a reliable tsunami early warning system (Katsumata et al. 2013). If this can be achieved, then a hazard reduction program can be developed in countries that are particularly prone to disastrous events, such as earthquakes and tsunamis.

We suggest that parameters of the Ina-TEWS should be revised. Our suggestion that Ina-TEWS should add parameters such as earthquake duration $\left(T_{0}\right)$, dominant period $\left(T_{\mathrm{d}}\right)$, and earthquake duration exceed to $50 \mathrm{~s}\left(t_{50 \mathrm{Ex}}\right)$ to improve its performance, because the parameters are more accurate than local magnitude, especially for tsunamigenic events (Lomax and Michelini 2011; Madlazim et al. 2015).

\section{Conclusions}

This study evaluated the performance of the Ina-TEWS as recorded by the BMKG in a region of the Indonesian archipelago during the period 2012-2015. Common earthquake parameters, such as the magnitude, origin time, depth, and the epicenters of the earthquake event were assessed. The data were compared with those provided by the Global CMT catalog. Although there were significant differences between the first three parameters given by these two institutions, the distribution of the earthquake epicenters largely agreed with each other. The performance of the Ina-TEWS needs to be improved to give better prediction and analyses of tsunamigenic earthquakes and to assess the risk of hazards from tsunamis in terms of both accuracy and speed. There needs to be an alternative method of analyzing tsunamigenic earthquakes that includes the rapid and accurate determination of earthquake magnitudes and depths.

Acknowledgments The authors sincerely thank the Indonesian Agency for Geophysics, Climatology and Meteorology (BMKG) in Jakarta and the Global CMT for providing full support for the data used in this work.

Open Access This article is distributed under the terms of the Creative Commons Attribution 4.0 International License (http://crea tivecommons.org/licenses/by/4.0/), which permits unrestricted use, distribution, and reproduction in any medium, provided you give appropriate credit to the original author(s) and the source, provide a link to the Creative Commons license, and indicate if changes were made.

\section{References}

Boore DM, Joyner WB, Fumal TE (1997) Equations for estimating horizontal response spectra and peak accelerations from western North American earthquakes: a summary of recent work. Seismol Res Lett 68(1):128-153

Delouis B, Charlety J, Vallée M (2009) A method for rapid determination of moment magnitude $M_{\mathrm{w}}$ for moderate to large earthquakes from the near-field spectra of strong-motion records (MWSYNTH). Bull Seismol Soc Am 99(3):1827-1840 
Dziewonski A, Chou TA, Woodhouse JH (1981) Determination of earthquake source parameters from waveform data for studies of global and regional seismicity. J Geophys Res 86:2825-2852

Ekström G (1994) Rapid earthquake analysis utilizes the internet. Comput Phys 8:632-638

Harjadi, Fauzi (2012) Development of Indonesia tsunami early warning system (InaTEWS) toward regional tsunami watch provider (RTWP). http://gfzpublic.gfzpotsdam.de/pubman/faces/ viewItemOverviewPage.jsp?itemId=escidoc:8171:4. Accessed 14 November 2015

Katsumata A, Ueno H, Aoki S, Yoshida Y, Barrientos S (2013) Rapid magnitude determination from peak amplitudes at local stations. Earth Planets Space 65:843-853

Kawakatsu H (1995) Automated near-realtime CMT inversion. Geophys Res Lett. doi:10.1029/95GL02341

Lomax A, Michelini A (2009) $M_{\mathrm{w}}$ pd: a duration-amplitude procedure for rapid determination of earthquake magnitude and tsunamigenic potential from $P$ waveforms. Geophys J Int 176(1):200-214

Lomax A, Michelini A (2011) Tsunami early warning using earthquake rupture duration and P-wave dominant period: the importance of length and depth faulting. Geophys J Int 176(1):283-291
Madlazim (2011) Towards an Indonesian tsunami early warning system by using rapid rupture duration calculation. Sci Tsunami Hazards 30(4):233-243

Madlazim (2013) Assessment of tsunami generation potential through rapid analysis of seismic parameters a case study: comparison of Sumatra earthquakes of 6 April and of 25 October 2010. Sci Tsunami Hazards 32(1):29-38

Madlazim Prastowo T, Hardy T (2015) Validation of Joko Tingkir Software using tsunami importance. Sci Tsunami Hazards 34(3):189-198

McCalpin JP (2010) Earthquake magnitude scale. Appendix 1. GEOHAZ Consulting Inc, Crestone

Ulutaş E (2013) Comparison of the seafloor displacement from uniform and non-uniform slip models on tsunami simulation of the 2011 Tohoku-Oki earthquake. J Asian Earth Sci 62:568-585. doi:10.1016/j.jseaes.2012.11.007

Ulutas E, Inan A, Annunziato A (2012) Web-based tsunami early warning system: a case study of the 2010 Kepulauan Mentawai earthquake and tsunami. Nat Hazards Earth Syst Sci 12:1855-1871. doi:10.5194/nhess-12-1-2012 